\title{
Extending electronegativities to superheavy Main Group atoms
}

\section{by Paul J. Karol}

UPAC recently published recommendations on rules for oxidation states within which was an endorsement of the electronegativity scale, called configuration energies, conceived by Allen and constructed from available calculated results. In conjunction with the International Year of the Periodic Table and the recognized extension of the Periodic Table through the end of its seventh period, it seemed timely to broaden those simple electronegativity calculations to include Main Group superheavy elements.

\section{Introduction}

Electronegativity, although not experimentally measureable, nevertheless is one of the most useful and central concepts to chemistry, starting primarily in introductory courses at college and pre-college levels, our target audience here. Its use in predicting and/or understanding chemical reactive behavior is well-appreciated. With the Periodic Table now covering the complete collection of elements within the range of atomic numbers $Z$ from 1 to 118 [1,2], it seems heuristically reasonable to explore the newest regime. Theoretical orbital energy calculations already available $[3,4]$ facilitate this venture that can actually be extended with a good degree of confidence to $Z=120$.

\begin{tabular}{|c|c|c|c|c|c|c|c|}
\hline H & \multicolumn{6}{|c|}{ Pauling Electronegativity Scale } & $\mathrm{He}$ \\
\hline $\begin{array}{c}\mathrm{Li} \\
0.98\end{array}$ & $\begin{array}{c}\mathrm{Be} \\
1.57\end{array}$ & $\begin{array}{c}B \\
2.04\end{array}$ & $\begin{array}{c}C \\
2.55\end{array}$ & $\begin{array}{c}N \\
3_{c} 04\end{array}$ & $\begin{array}{c}\text { (1) } \\
3.44\end{array}$ & $\begin{array}{c}F \\
3.98\end{array}$ & $\mathrm{Ne}$ \\
\hline $\begin{array}{c}\mathrm{Na} \\
0.93\end{array}$ & $\begin{array}{c}\mathrm{Mg} \\
1.31\end{array}$ & $\begin{array}{c}\text { Al } \\
1.61\end{array}$ & $\begin{array}{c}\mathrm{Si} \\
1.90\end{array}$ & $\begin{array}{c}P \\
2.19\end{array}$ & $\begin{array}{c}\$ \\
2.58\end{array}$ & $\begin{array}{c}\mathbb{C} \\
3.76\end{array}$ & $\mathrm{Ar}$ \\
\hline $\begin{array}{c}K \\
0.82\end{array}$ & $\begin{array}{c}\mathrm{Ca} \\
1.00\end{array}$ & $\begin{array}{c}\mathrm{Ga} \\
1.81\end{array}$ & $\begin{array}{c}\mathrm{Ge} \\
2.01\end{array}$ & $\begin{array}{c}\text { As } \\
2.18\end{array}$ & $\begin{array}{c}\mathrm{Se} \\
2.55\end{array}$ & $\begin{array}{c}\mathrm{Br} \\
2.96\end{array}$ & $\mathrm{Kr}$ \\
\hline $\begin{array}{c}R b \\
0.82\end{array}$ & $\begin{array}{c}\mathrm{Sr} \\
0.95\end{array}$ & $\begin{array}{l}\text { In } \\
1.78\end{array}$ & $\begin{array}{c}\text { Sn } \\
1.96\end{array}$ & $\begin{array}{c}\mathrm{Sb} \\
2.05\end{array}$ & $\begin{array}{l}\mathrm{Te} \\
2.1\end{array}$ & $\begin{array}{c}1 \\
2.66\end{array}$ & Xe \\
\hline $\begin{array}{c}\text { Cs } \\
0.79\end{array}$ & $\begin{array}{c}\mathrm{Ba} \\
0.89\end{array}$ & $\begin{array}{c}\mathrm{TI} \\
1.62\end{array}$ & $\begin{array}{c}\mathrm{Pb} \\
1.87\end{array}$ & $\begin{array}{c}B \mathrm{Bi} \\
2.02\end{array}$ & $\begin{array}{l}\text { Po } \\
2.0\end{array}$ & $\begin{array}{l}\text { At } \\
2.2\end{array}$ & Rn \\
\hline $\begin{array}{c}\mathrm{Fr} \\
0.7\end{array}$ & $\begin{array}{l}\mathrm{Ra} \\
0.9\end{array}$ & $\mathrm{Nh}$ & FI & Mc & Lv & Ts & $\mathrm{Og}$ \\
\hline eka-Fr & eka-Ra & & & & & & \\
\hline
\end{tabular}

Fig. 1: Pauling electronegativity values for Main Group elements. Colors are to guide the eye towards increasing electronegativity.

\section{Pauling Electronegativities}

The Gold Book [5], IUPAC's Compendium of Chemical Terminology, refers to electronegativity as a concept introduced by L. Pauling [6] measuring the qualitative property that a chemist calls electronegativity as "the power of an atom to attract electrons to itself." With the above empirical definition, electronegativity is an atom-in-molecule property, not an invariant property of the atom but a property dependent on the atom's environment in the molecule, on the number and types of atoms attached to it, on the atom's oxidation state. Recently, Rahm et al. have proposed extending the concept to include the external influence of compression [7]. Pauling's electronegativity values for the Main Group elements are illustrated in Figure 1. The periodic trends going across rows and down groups (columns) are evident and underly the usual discussion about electronegativity behavior.

\section{Other Electronegativity Schemes}

Other approaches espousing the view that electronegativity is a property of atoms in molecules also give multiple values for an atom, taking into account the oxidation state and molecular environment including the influence of solvation. Since the Gold Book also has entries on group electronegativities or substituent electronegativities, it seems reasonable to refer to atomic electronegativities (or perhaps to intrinsic electronegativities) when focusing on a property characteristic of a free atom. In that regard, as emphasized by the recent endorsement by IUPAC in their codification of oxidation states $[8,9]$, the electronegativity hypothesis introduced by Allen and collaborators is advantageous and produces very reasonable values in qualitative agreement with other assignment venues although the transition elements are problematic and the inner transition elements were not addressed. Up-to-date comprehensive reviews of electronegativity have been published recently by Politzer and Murray [10] and by Rahm et al. [7,11,12], each of which acknowledge both the simplicity and accuracy of the Allen electronegativities for Main Group elements but definitely not for the transition and inner transition elements. Cao et al. [13] review the role of electronegativity as one of the main determinants of chemical behavior. Our particular argument here is not to sponsor nor review any particular scheme but rather to employ the one that seems both successful and uniquely applicable to extending the Periodic Table at this time and one that has been embraced by IUPAC $[8,9]$. 


\section{Allen Electronegativities}

Attraction of an atom to its electrons is arguably quantified by the electron energies, negative relative to the binding threshold. Allen et al. [3,4] have logically identified an electronegativity scheme measuring the difficulty with which an atom yields its valence electron. The Allen scheme is not as fundamentally grounded as are many of the alternatives. It is quantitatively embodied in what they call the configuration energy $\left(\mathrm{CE}\right.$, symbol $E_{\mathrm{c}}$ ): the average orbital energy of valence electrons in ground-state isolated atoms according to

$$
E_{\mathrm{c}}=\frac{n_{\mathrm{s}} \varepsilon_{\mathrm{s}}+n_{\mathrm{p}} \varepsilon_{\mathrm{p}}}{n_{\mathrm{s}}+n_{\mathrm{p}}}
$$

in which $n_{\mathrm{s}}$ and $n_{\mathrm{p}}$, respectively, are the numbers of $s-$ and $p$-valence electrons in the ground state configuration for the Main Group elements we are restricting our considerations to here. Orbital energies for these electrons are indicated by $\varepsilon_{\mathrm{s}}$ and $\varepsilon_{\mathrm{p}}$, respectively, and the latter are $j$-multiplet-averaged: $(2 j+1)$. They approximate ionization energies.
In their publication, Allen et al. use experimentally determined spectroscopic electronic energies, $\varepsilon$, when available, as through the NIST Atomic Spectra Database (www.nist.gov/pml) tabulations. Alternatively, and in the cases of experimentally unknown energies, theoretical values for orbital eigenvalues determined by Dirac-Fock calculations can be employed. Allen et al. actually use Dirac-Hartree-Fock calculations acknowledging these compare very favorably with available Dirac-Fock results. Experimental (spectroscopic) and theoretical (Dirac-Fock) final orbital energy values differ only slightly, $1 \%$ or less in most cases as noted by Allen et al. [3,4] (q.v.). Theoretical Dirac-Fock values through $Z=120$ have been published by Desclaux [14] and nowhere else to date. Table 1 has the calculated valence energies for Main Group elements from rows 6 and 7 of the Periodic Table, extending to the yet undiscovered $s$-block elements with $Z=119$ and 120 beginning the eighth row. Unit of the energy is $E_{\mathrm{h}}$ (hartree) with ( $1 E_{\mathrm{h}}$ approximately $\left.27.21 \mathrm{eV}\right)$. The configuration energies are calculated according to eq. 1 from the ground state valence orbital configurations indicated in the first column. These are proportionately

\begin{tabular}{|c|c|c|c|c|c|c|c|}
\hline Atom A.. $\mathbf{s}^{n} \mathbf{p}^{m}$ & $\begin{array}{l}\mathcal{E}_{\mathrm{s}}(\text { calc }) \\
/ E_{\mathrm{h}}\end{array}$ & $\begin{array}{l}\varepsilon_{p} \text { (calc) } \\
/ E_{h}\end{array}$ & $\begin{array}{l}\varepsilon_{\mathrm{s}}(\mathrm{spec}) \\
/ E_{\mathrm{h}}\end{array}$ & $\begin{array}{l}\mathcal{E}_{\mathrm{p}} \text { (spec) } \\
/ E_{\mathrm{h}}\end{array}$ & $E_{\mathrm{c}}$ & $\chi_{A}$ (theory) & $\chi_{A}($ spec $)$ \\
\hline Cs...s ${ }^{1}$ & 0.2561 & -- & 0.2865 & & 0.2561 & 0.59 & 0.66 \\
\hline Ba... $\mathrm{s}^{2}$ & 0.3260 & -- & 0.3830 & & 0.3260 & 0.75 & 0.88 \\
\hline TI... ${ }^{2} p^{1}$ & 0.8984 & 0.3763 & 0.9656 & 0.4019 & 0.7206 & 1.67 & 1.79 \\
\hline$P b . . s^{2} p^{2}$ & 1.1330 & 0.4766 & 1.1111 & 0.5008 & 0.8017 & 1.85 & 1.85 \\
\hline Bi...s $p^{2} p^{3}$ & 1.3724 & 0.5739 & $1.288^{1 a}$ & 0.5990 & 0.8905 & 2.06 & $2.01^{a}$ \\
\hline Po... $\mathrm{s}^{2} \mathrm{p}^{4}$ & 1.6197 & 0.6715 & $1.474^{a}$ & $0.692^{\mathrm{a}}$ & 0.9849 & 2.27 & $2.19^{a}$ \\
\hline At... ${ }^{2} p^{5}$ & 1.8763 & 0.7707 & $1.685^{\mathrm{a}}$ & $0.787^{a}$ & 1.1126 & 2.50 & $2.39^{a}$ \\
\hline $\operatorname{Rn} . \mathrm{s}^{2} \mathrm{p}^{6}$ & 2.1429 & 0.8723 & $1.872^{\mathrm{a}}$ & 0.8845 & 1.1875 & 2.74 & $2.60^{a}$ \\
\hline Fr..s ${ }^{1}$ & 0.2654 & -- & & & 0.2654 & 0.61 & \\
\hline Ra...s $s^{2}$ & 0.3325 & -- & & & 0.3325 & 0.76 & \\
\hline Nh... $s^{2} p^{1}$ & 1.1762 & 0.3780 & & & 0.9101 & 2.09 & \\
\hline $\mathrm{FI} . . \mathrm{s}^{2} \mathrm{p}^{2}$ & 1.4429 & 0.4827 & & & 0.9628 & 2.21 & \\
\hline Mc... $s^{2} p^{3}$ & 1.7150 & 0.5847 & & & 1.0368 & 2.38 & \\
\hline LV... ${ }^{2} p^{4}$ & 1.9961 & 0.6874 & & & 1.1236 & 2.58 & \\
\hline Ts... $s^{2} p^{5}$ & 2.2878 & 0.7924 & & & 1.2204 & 2.81 & \\
\hline Og... $s^{2} p^{6}$ & 2.5913 & 0.9005 & & & 1.3232 & 3.04 & \\
\hline eka-Fr..s' & 0.3177 & -- & & & 0.3177 & 0.73 & \\
\hline eka-Ra...s² & 0.3835 & -- & & & 0.3835 & 0.88 & \\
\hline
\end{tabular}

Table 1: Calculated (Dirac-Fock) and experimental (spectroscopic) s, p orbital energies, the resulting configuration energies ( $E_{\mathrm{c}}$, eq. 1), all in hartree. Electronegativities ( $E N$, symbol $\chi_{\mathrm{A}}$ ) from calculations (theory) and spectroscopic measurements (spec) are scaled according to $\chi_{\mathrm{A}}=2.30016 E_{\mathrm{c}}$. 


\section{Extending electronegativities to superheavy Main Group atoms}

\begin{tabular}{|c|c|c|c|c|c|c|c|}
\hline $\mathrm{H}$ & \multicolumn{6}{|c|}{ Allen Electronegativity Scale } & $\mathrm{He}$ \\
\hline $\begin{array}{c}\mathbf{L i} \\
0.91\end{array}$ & $\begin{array}{c}\mathrm{Be} \\
1.58\end{array}$ & $\begin{array}{c}\text { B } \\
2.05\end{array}$ & $\begin{array}{c}C \\
2.54\end{array}$ & $\begin{array}{c}N \\
3.07\end{array}$ & $\begin{array}{c}(1) \\
3.61\end{array}$ & $\begin{array}{c}E \\
4.79\end{array}$ & $\begin{array}{c}\mathrm{Ne} \\
4,79\end{array}$ \\
\hline $\begin{array}{c}\mathrm{Na} \\
0.87\end{array}$ & $\begin{array}{c}\mathrm{Mg} \\
1.29\end{array}$ & $\begin{array}{c}\text { Al } \\
1.61\end{array}$ & $\begin{array}{c}\mathrm{Si} \\
1.92\end{array}$ & $\begin{array}{c}P \\
2.25\end{array}$ & $\begin{array}{c}S \\
2.59\end{array}$ & $\begin{array}{c}\text { Cl } \\
2.87\end{array}$ & $\begin{array}{c}\mathrm{Al} \\
3.24\end{array}$ \\
\hline $\begin{array}{c}K \\
0.73\end{array}$ & $\begin{array}{c}\mathrm{Ca} \\
1.03\end{array}$ & $\begin{array}{c}\mathrm{Ga} \\
1.76\end{array}$ & $\begin{array}{c}\mathrm{Ge} \\
1.99\end{array}$ & $\begin{array}{c}\text { As } \\
2.21\end{array}$ & $\begin{array}{c}\mathrm{Se} \\
2.42\end{array}$ & $\begin{array}{c}\mathrm{Br} \\
2.69\end{array}$ & $\begin{array}{c}\mathrm{Kr} \\
2.97\end{array}$ \\
\hline $\begin{array}{c}\mathrm{Rb} \\
0.71\end{array}$ & $\begin{array}{c}\mathrm{Sr} \\
0.96\end{array}$ & $\stackrel{\ln }{1.66}$ & $\begin{array}{c}\text { Sn } \\
1.82\end{array}$ & $\begin{array}{c}\mathrm{Sb} \\
1.98\end{array}$ & $\begin{array}{c}\mathrm{Te} \\
2.16\end{array}$ & $\begin{array}{c}1 \\
2.36\end{array}$ & $\begin{array}{c}X_{e} \\
2.58\end{array}$ \\
\hline $\begin{array}{c}\text { Cs } \\
0.66\end{array}$ & $\begin{array}{c}\mathrm{Ba} \\
0.88\end{array}$ & $\begin{array}{c}\mathrm{TI} \\
1.79\end{array}$ & $\begin{array}{c}\mathrm{Pb} \\
1.85\end{array}$ & $\begin{array}{c}B i \\
2.06\end{array}$ & $\begin{array}{c}\text { Po } \\
2.27\end{array}$ & $\begin{array}{c}\text { At } \\
2.50\end{array}$ & $\begin{array}{c}\text { Rn } \\
2.74\end{array}$ \\
\hline $\begin{array}{c}\mathrm{Fr} \\
0.61\end{array}$ & $\begin{array}{c}\mathrm{Ra} \\
0.76\end{array}$ & $\begin{array}{c}\text { Nh } \\
2.09\end{array}$ & $\begin{array}{c}\mathrm{FI} \\
2.21\end{array}$ & $\begin{array}{c}\text { Mc } \\
2.38\end{array}$ & $\begin{array}{l}\text { LV } \\
2.58\end{array}$ & $\begin{array}{c}\text { Ts } \\
2.81\end{array}$ & $\begin{array}{c}\mathrm{Og} \\
3.04\end{array}$ \\
\hline $\begin{array}{c}\text { eka-Fr } \\
0.73\end{array}$ & $\begin{array}{c}\text { eka-Ra } \\
0.88\end{array}$ & & & & & & \\
\hline
\end{tabular}

Fig. 2: Periodic Table of all Main Group element Allen electronegativities. Values through $P b$ are from reference [4]. The superheavy ( $Z>103)$ Main Group element electronegativities are from this work.

rescaled, as by Allen et al., to electronegativities (EN) closely matching those of Pauling using the multiplicative factor 2.300 16. The preferred choice is to use the spectroscopically-determined values when available (through $\mathrm{Pb}$ ) and the theoretical values for the rest. Complete results for Main Group elements are illustrated in Figure 2.

As with the previous scales, electronegativity increases from left to right across each row from alkali metal to noble element as is illuminated in Figure 3, monotonically in most cases. However, the monotonic drop in electronegativities proceeding down any group column reverses as the heavy elements are approached. This is most likely a reflection of relativistic effects in which the valence electrons are drawn in

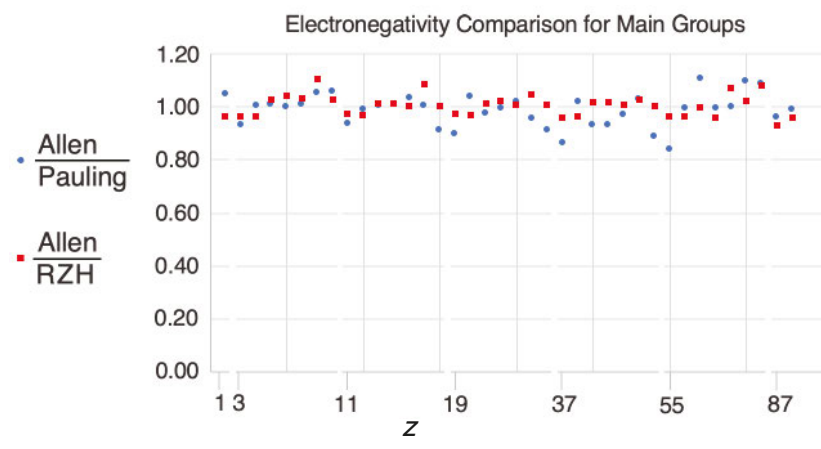

Fig. 4: Demonstrating how the Allen electronegativities concur with those of the commonly advocated Pauling electronegativities and with the Rahm, Zeng, Hoffmann (RZH) electronegativities established for Main Group elements obtained from Reference 12

closer to the nucleus and are more difficult to "move".

Figure 4 shows the relative value of each Allen electronegativity from Figure 2 compared to its Pauling electronegativity counterpart from Figure 1 for the Main Group elements exclusive the noble gases. Also displayed are the values from the very recent stratagem advocated by Rahm et al. [11]. The concurrence lends credibility to the extension of calculated Main Group heavy element electronegativities advocated in this work and, pending future more sophisticated theoretical calculations, will not be expected to be significantly modified. Their likely use in anticipating the chemistry of new elements $[15,16]$ is reasonable as we enjoy speculating on where the International Year of the Periodic Table leads us.

\section{References}

1. P. Karol, R. Barber, B. Sherrill, E. Vardaci, T. Yamazak (IUPAC Technical Report). Pure Appl. Chem. 88, 155 (2016); https://doi.org/10.1515/pac-2015-0501

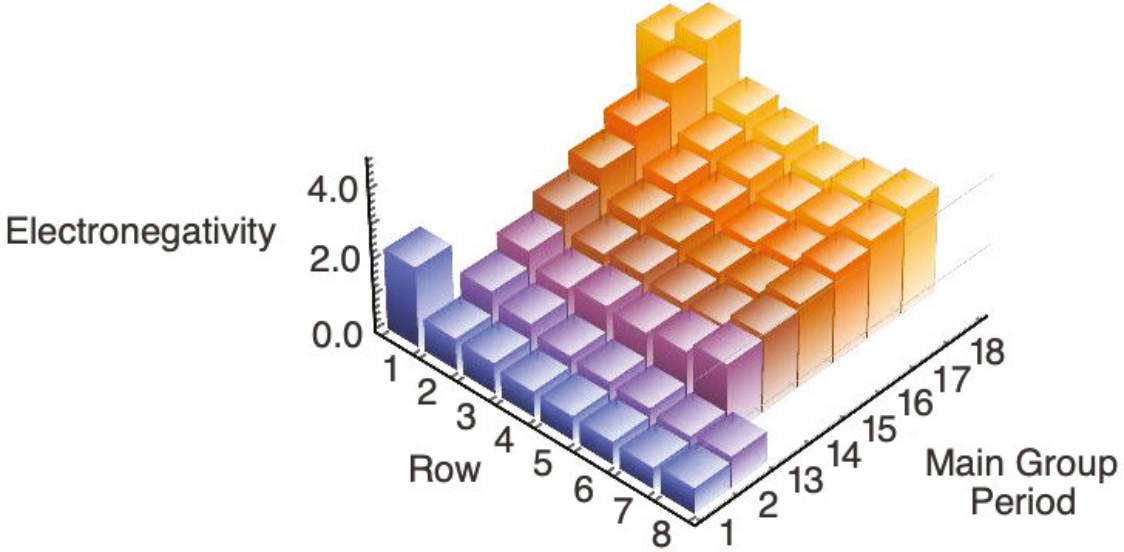

Fig. 3: Three-dimensional display of Main Group element Allen electronegativities in a Periodic Table format starting on the left, row 1, with hydrogen. 


\section{Extending electronegativities to superheavy Main Group atoms}

2. P. Karol Heavy, Superheavy...Quo Vadis?. Mendeleev to Oganesson, (E. Scerri and G. Restrepo eds). Chapt. 1, 8-42, Oxford University Press, New York (2018).

3. L. C. Allen J. Am. Chem. Soc. 111, 9003 (1989).

4. J. Mann, T. Meek, L. Allen J. Am. Chem. Soc. 122, 2780 (2000).

5. IUPAC. Compendium of Chemical Terminology, 2nd ed (the „Gold Book"). Compiled by A. D. McNaught and A. Wilkinson. Blackwell Scientific Publications, Oxford (1997). Online version (2019-) created by S. J. Chalk. ISBN 0-9678550-9-8. https://doi.org/10.1351/goldbook.

6. L. Pauling L. J. Am. Chem. Soc. 54, 3570 (1932).

7. M. Rahm, R. Cammi, N. W. Ashcroft, R. Hoffmann, J. Am. Chem. Soc. 141, 10253-10271 (2019).

8. P. Karen, P. McArdle, J. Takats (IUPAC Technical Report). Pure Appl. Chem. 86, 1017 (2014); https://doi. org/10.1515/pac-2013-0505

9. P. Karen, P. McArdle, J. Takats (IUPAC Recommendations 2016) Pure Appl. Chem. 88, 831 (2016); https://doi.org/10.1515/pac-2015-1204

10. P. Politzer, J. S. Murray, J. Molec. Mod. 24, 214 (2018).
11. M. Rahm, R. Hoffmann, J. Am. Chem. Soc. 137, 10282-10291 (2015).

12. M. Rahm, T. Zeng, R. Hoffmann J. Am. Chem. Soc. 141, 342 (2019).

13. C.-S. Cao, H.-S. Hu, J. Li, W. H. Eugen Schwarz Pure Appl. Chem. 91, 1969 (2019).

14. J. P. Desclaux Atomic Data and Nuclear Data Tables 12, 311 (1973).

15. V. Pershina Inorg. Chem. 57, 3948 (2018).

16. A. Türler, V. Pershina Chem. Rev. 113, 1237 (2013).

\section{Acknowledgements}

The author acknowledges and appreciates the comments from the ACS Committee on Nomenclature, Terminology, and Symbols of which the author was a member and former Chair.

Paul J. Karol, https://orcid.org/0000-0002--3555-6899

\section{Continued from page 11}

3. Yaga, D., Mell., P., Roby, N., Scarfone, K., NISTIR 8202 Blockchain Technology Overview, National Institute of Standards and Technology, U. S. Department of Commerce, January 2018.

4. Merkle Trees, Wikipedia, see; https://en.wikipedia.org/ wiki/Merkle_tree (last accessed 16 February 2020).

5. "Blockchain: Background and Policy Issues," Congressional Research Services Report R45116, https://crsreports.congress.gov/product/pdf/R/R45116 (last accessed 16 February 2020).

6. Casey, N. J., Vigna, P., "In Blockchain We Trust," MIT Technology Review, Vo. 121, No. 3, May/June

7. Blockchain for Scholarly Publishing, presented by the National Federation of Advanced Information Services (NFAIS) in Alexandria, VA, USA, 15-16 May 2018; see: https://nfais.memberclicks.net/2018-blockchainprogram (last accessed 16 February 2020).

8. Editor, "Dave Kochalko Interview: How Technology could restore trust in science publishing," The SciencePod Magazine, 20 March 2019, https:// sciencepod.org/2019/03/20/dave-kochalko-interviewhow-technology-could-restore-trust-in-sciencepublishing/ (last accessed 16 February 2020).

9. "The Novel Blockchain Consortium for Science: bloxberg@Blockchain Munich Meetup," 19 October 2018, see: https://www.mpdl.mpg.de/en/about-us/ news/488-the-novel-blockchain-consoritum-forscience-bloxberg-blockchain-munich-meetup.html (last accessed 16 February 2020).

10. For more information see: https://bloxberg.org/ and https://bloxberg.org/wp-content/uploads/2019/07/ bloxberg_whitepaper.pdf (last accessed 16 February 2020)

11. "Gartner Hype Cycle." See: https://whatis.techtarget. com/definition/Gartner-hype-cycle (last accessed 16 February 2020).

12. Gartner 2019 Hype Cycle Shows Most Blockchain Technologies Are Still Five to 10 Years Away From Transformational Impact, Press Release, Gartner Technologies, 8 October 2019; see: https://www.gartner.com/en/newsroom/ press-releases/2019-10-08-gartner-2019-hypecycle-shows-most-blockchain-technologies-are-stillfive-to-10-years-away-from-transformational-impact (last accessed 16 February 2020).

13. Adams, D., The Salmon of Doubt: Hitchhiking the Galaxy one Last Time, Ballantine Books, New York, 2003.

14. "Roy Amara," https://en.wikipedia.org/wiki/Roy_Amara, (last accessed 16 February 2020).

15. Lawlor, B., "An Overview of the NFAIS Conference: Blockchain for Scholarly Publishing," Information Services and Use, Vol. 38, Issue 3, 2018, available at: https://content.iospress.com/journals/informationservices-and-use/38/3 (last accessed 16 February 2020).

Bonnie Lawlor was Chair of IUPAC Committee on Publications and Cheminformatics Data Standards from 2014-2019 and is Secretary of Chemistry International Editorial Board. 